\title{
Evaluation of Microstructure and Mechanical Properties at the Interface Region of Laser-Clad Stellite 6 on Steel Using Nanoindentation
}

\author{
Novana Hutasoit · Wenyi Yan · Ryan Cottam • \\ Milan Brandt $\cdot$ Aaron Blicblau
}

Received: 16 June 2013/Accepted: 6 September 2013/Published online: 10 October 2013

(C) Springer Science+Business Media New York and ASM International 2013

\begin{abstract}
The interface area in laser cladding, microstructures and mechanical properties of which determine the structural integrity of the laser-deposited coating, consists of two distinctive zones: the dilution and heataffected zones (HAZs). The dilution region is the region where melted substrate forms a mixture with coating material and possesses microstructure similar to the coating. The HAZ is the region that lies in the substrate but possesses different microstructures compared with original substrate due to heat transfer from melt pool during processing. There are limited data available on mechanical properties of the dilution and HAZ and, in this study, the mechanical properties of the two regions have been evaluated using nanoindentation. This testing technique has the ability to resolve the mechanical properties at fine spacings, unlike microhardness testing and conventional mechanical testing. Stellite 6 powder was deposited onto a round bar AISI 4130 steel using a continuous wave Nd:YAG laser. The effect of laser cladding process on the microstructure, hardness, and elastic modulus of the coating, at the interface has been examined by nanoindentation testing. The elastic modulus of the substrate measured was found to be $198.76 \pm 24.96 \mathrm{GPa}$, which is in a good
\end{abstract}

N. Hutasoit $(\bowtie) \cdot$ R. Cottam $\cdot$ A. Blicblau

Industrial Research Institute Swinburne, Faculty of Engineering and Industrial Science, Swinburne University of Technology, Hawthorn, VIC 3120, Australia

e-mail: nhutasoit@swin.edu.au

W. Yan

Department of Mechanical and Aerospace Engineering, Monash University, Clayton, VIC 3800, Australia

M. Brandt

School of Aerospace, Mechanical and Manufacturing

Engineering, RMIT University, Bundoora, VIC 3083, Australia agreement with the standard elastic modulus of AISI 4130 reported in literature. For the laser clad specimen, dilution area showed elastic modulus of $192.62 \pm 7.67 \mathrm{GPa}$, slightly higher than the average elastic modulus of the HAZ, $189.94 \pm 14.75$. This is due to the dilution area containing a mixture mainly of $\mathrm{Fe}, \mathrm{Cr}$ and $\mathrm{Co}$. The increased level of $\mathrm{Fe}$ in this dilution area leads the tendency of this region to behave as substrate.

Keywords Laser cladding $\cdot$ Dilution $\cdot$ Heat-affected zone mechanical properties $\cdot$ Nanoindentation

\section{Introduction}

Laser cladding is a laser-surfacing technique that can enhance the properties and/or regenerate surface of a component. In laser cladding, heat from laser energy melts a small region of the substrate into which coating material is injected and fuses the coating material to the substrate, thus producing a new layer with sound metallurgical bond (illustrated in Fig. 1). In the presence of different structures and properties of clad and substrate, laser cladding product can be considered as a bi-material system or composite.

One of the important issues in laser cladding is the formation of diluted zone: a region where mixing of chemical elements from substrate and coating material occurs, which can degrade the properties of the coating material. Dilution level is defined as the ratio of melted substrate area $\left(\mathrm{A}_{1}\right)$ to the total molten area $\left(A_{1}+A_{1}^{c}\right)$ (Fig. 2). Dilution is known to affect the hardness $[1,2]$ and wear property of clad layer [3-5]. Compared with other thermo-mechanical processes, laser cladding is capable to produce lower dilution levels [3, $6,7]$ and finer microstructure in clad layer $[7,8]$. The heataffected zone (HAZ) that lies in substrate, below the dilution 


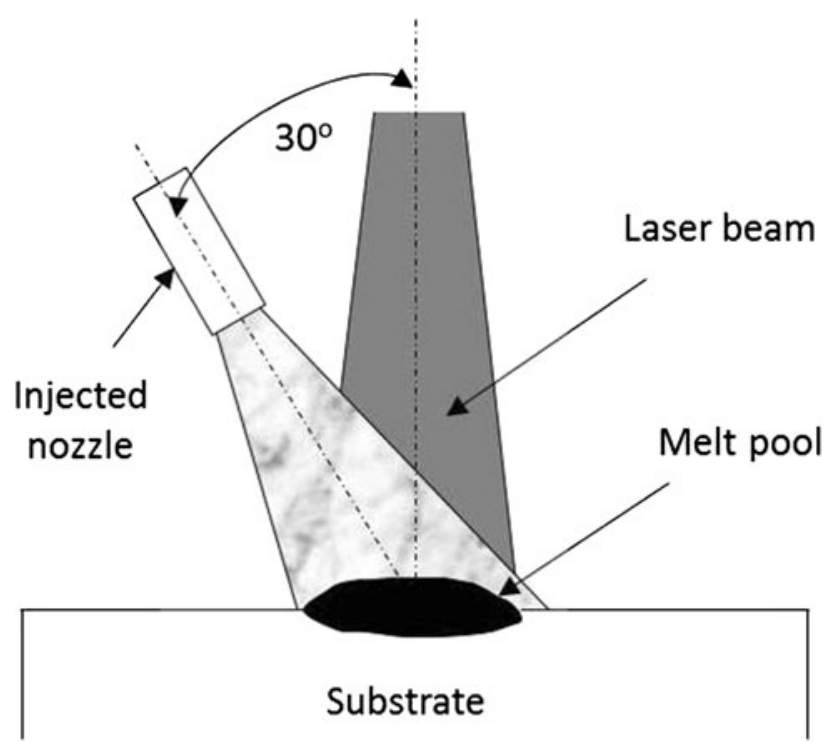

Fig. 1 Schematic illustration of laser cladding process

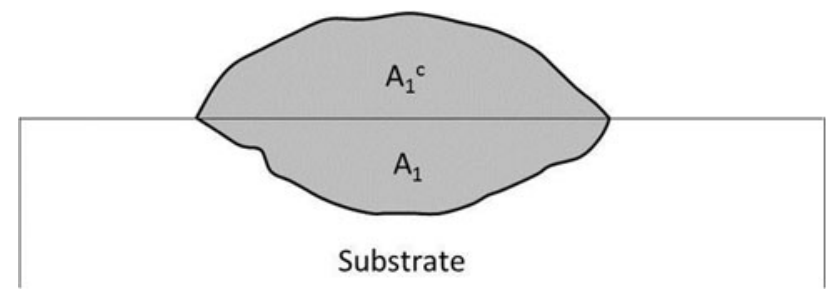

Fig. 2 Schematic illustration of dilution

region (Fig. 2) also shows a variation in properties of the material that can be detrimental in certain applications. In terms of bi-material system, fracture behaviour of this system was found governed by yield strength and elastic modulus of the two different layers of material. Several studies [9, 10] have shown that in a bi-material system component, the differences in yield strengths and elastic moduli of the two materials affect whether the crack will propagate into the substrate material along the interface, or bifurcate at the interface. Other studies on bond strengths of laser-clad specimens showed that cracks initiated and propagated along the area at the vicinity of dilution region due to the presence of lower strength phases [11, 12].

Despite the need of further understanding of mechanical properties of clad layer and the substrate in assessing the performances, very limited study towards characterization of laser-clad structure is available. The main reason for the limited study is due to the two region's geometry and small size, is not conducive for conventional mechanical tests, therefore, requiring the development of other material characterization methods.

Nanoindentation testing which is used for characterization of thin (micrometer) layer coating could be used to study the interface region produced during laser cladding. Nanoindentation testing is designed to sense and record indentation depth in nanometer $(\mathrm{nm})$ scale and loads in $\mathrm{mN}$ resolution and produce load versus displacement curve or $P-h$ curve. Depending on the type and geometry of the indenter, with reference of the $P-h$ curve, various material properties can be calculated, i.e. hardness, elastic modulus and fracture toughness using Berkovich-type indenter [13]. In this study, by utilizing instrumented nanoindentation method, mechanical properties, primarily elastic modulus of the dilution zone and HAZ in a laser clad were investigated and related to the bulk properties of the clad.

\section{Experimental}

\section{Laser Cladding and Microstructural Examination}

The substrates and coating materials used in this experiment were of AISI 4130 steel and Stellite 6, respectively; the chemical compositions of the two materials are shown in Table 1. AISI 4130 steel is one type of high-strength low-alloy steel [29], commonly used in the manufacture of crankshafts for power plant [14], for automotive application [15], shaft of turbocharger [16], and aircraft components [17]. Round bar of AISI 4130 steel, with a diameter of $5.5 \mathrm{~mm}$, was laser clad with Stellite 6 powder with the powder size range of $45-150 \mu \mathrm{m}$. Stellite 6 is a Co-based coating material that possesses superior high-temperature wear [4]. Laser cladding was performed with a fibredelivered Nd:YAG Rofin Sinar laser, at $550 \mathrm{~W}$, spot size $3 \mathrm{~mm}$ in diameter and with Argon shielding gas. Laser cladding was conducted with linear scan speed of $500 \mathrm{~mm} /$ min, using Stellite 6 powder which was injected using an off-axis nozzle inclined at $60^{\circ}$ to the substrate surface with powder feed rate of $4 \mathrm{~g} / \mathrm{min}$. Multiple tracks and multiple layers of Stellite 6 were deposited onto a round bar AISI

Table 1 Chemical composition of AISI 4130 steel and Stellite 6

\begin{tabular}{llllllllllll}
\hline & \multicolumn{1}{l}{ Composition (wt.\%) } \\
\cline { 2 - 10 } & Fe & C & Mn & P & S & Si & Cr & Mo & Co & Ni \\
\hline AISI 4130 [29] & Bal & $0.28-0.33$ & $0.40-0.60$ & $0.035 \max$ & $0.04 \max$ & $0.15-0.30$ & $0.80-1.10$ & $0.15-0.25$ & $\ldots$ & $\ldots$ & $\ldots$ \\
Stellite 6 [32] & 3 & 1.2 & 1 & $\ldots$ & $\ldots$ & 1.5 & 29 & 1.5 & Bal & 3 & 4.5 \\
\hline
\end{tabular}




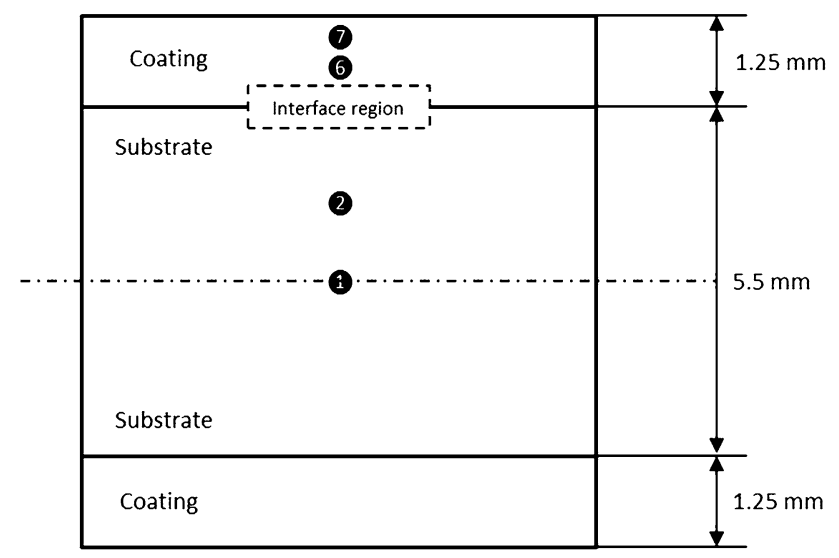

Fig. 3 EDS inspection location across substrate indicated by locations 1 and 2; and across coating indicated by locations 6 and 7

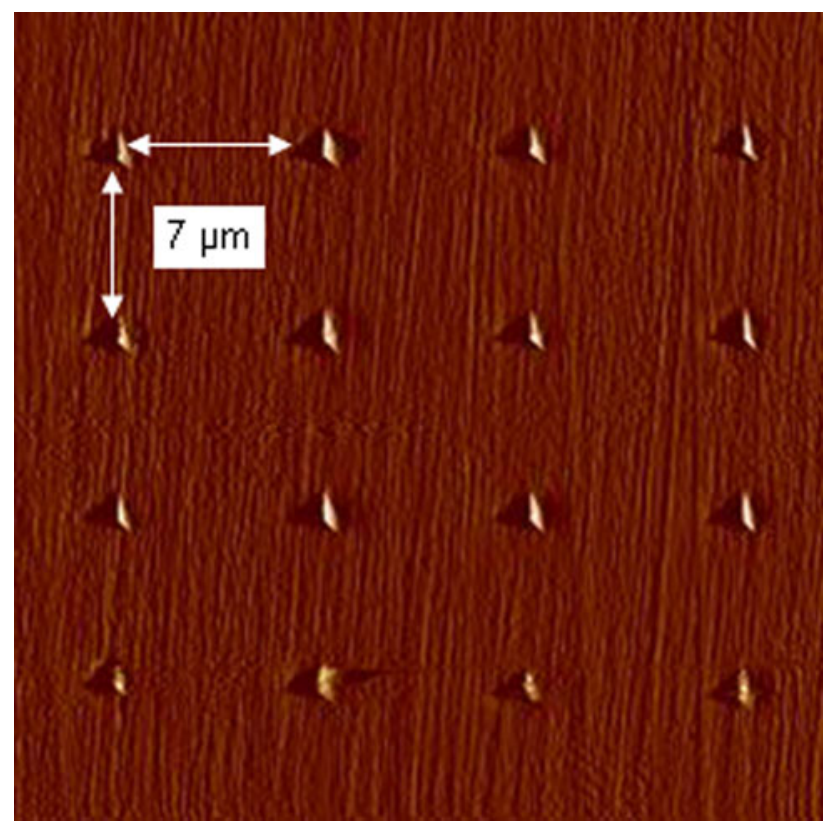

Fig. 4 EDS inspection location at the vicinity of interface indicated by location 3 (at HAZ), location 4 and 5 (at dilution region), refer to inset of interface area in Fig. 3

4130 steel substrate surface until the final diameter of specimen reached the value of $8.3 \mathrm{~mm}$. After cladding, the specimen was placed in vermiculate to allow for cooling slowly to room temperature.

Chemical element measurements were performed using an energy dispersive $\mathrm{x}$-ray spectroscopy (EDS) unit, at two locations - in the substrate area (at the centre and middle of the substrate and in the HAZ) and coating region (two locations at dilution region and one location at top of coating)-as shown in Fig. 3. As for inspection at locations in the vicinity of interface, each location was separated by around $50 \mu \mathrm{m}$ (Fig. 4). It should be noted that the result of the EDS technique is only an indication of the chemical composition and is not an absolute value.
Specimens before and after laser cladding were cut in transverse direction and polished down to $1 \mu \mathrm{m}$ using diamond paste followed by etching the polished specimen in $2 \%$ Nital solution to reveal the microstructures. The microstructure of Stellite 6 was revealed by electrolytic etching in $2 \%$ Nital solution under $8-10 \mathrm{mV}$ power. Micro Vickers hardness measurements were performed under $100 \mathrm{~g}$ loads to measure the hardness of coating and substrate.

\section{Nanoindentation}

\section{Methodology}

The reference of instrumented nanoindentation method to probe hardness and elastic modulus utilized in this study was the method developed by Oliver-Pharr [18]. This method commences by fitting the unloading curve according to power law relation as below:

$P=B\left(h-h_{\mathrm{f}}\right)^{m}$,

where $P$ is the indentation load, $h$ is the displacement, $B$ and $m$ are the fitting parameters and $h_{\mathrm{f}}$ is the final displacement after complete unloading calculated from curve fitting. From these data, contact stiffness is established by differentiating Eq 1 at the maximum depth of penetration, $h=h_{\max }$ :

$S=\frac{\mathrm{d} P}{\mathrm{~d} h}=m B\left(h_{\max }-h_{\mathrm{f}}\right)^{m-1}$.

The obtained contact stiffness from $\mathrm{Eq} 2$ is used to estimate the contact depth, $h_{\mathrm{c}}$, under the maximum indentation load:

$h_{\mathrm{c}}=h_{\max }-\varepsilon \frac{P_{\max }}{S}$,

where $P_{\max }$ is the maximum load, and $\varepsilon$ is a constant referring to indenter geometry: in this case, 0.75 for Berkovich indenter. Contact depth information is required to estimate the projected contact area, A, of the hardness impression:

$A=\pi\left(h_{\mathrm{c}} \tan \theta\right)^{2}$.

Contact area computed using $\mathrm{Eq} 4$ is used to compute the effective elastic modulus, $E_{\text {eff }}$, using the formula as follows:

$E_{\text {eff }}=\frac{1}{\beta} \frac{\sqrt{\pi}}{2} \frac{S}{\sqrt{A}}$,

where $\beta$ is a constant referring to indenter geometry, for Berkovich indenter the value of $\beta$ is 1.034 [18]. Finally, elastic modulus can be computed using the formula: 


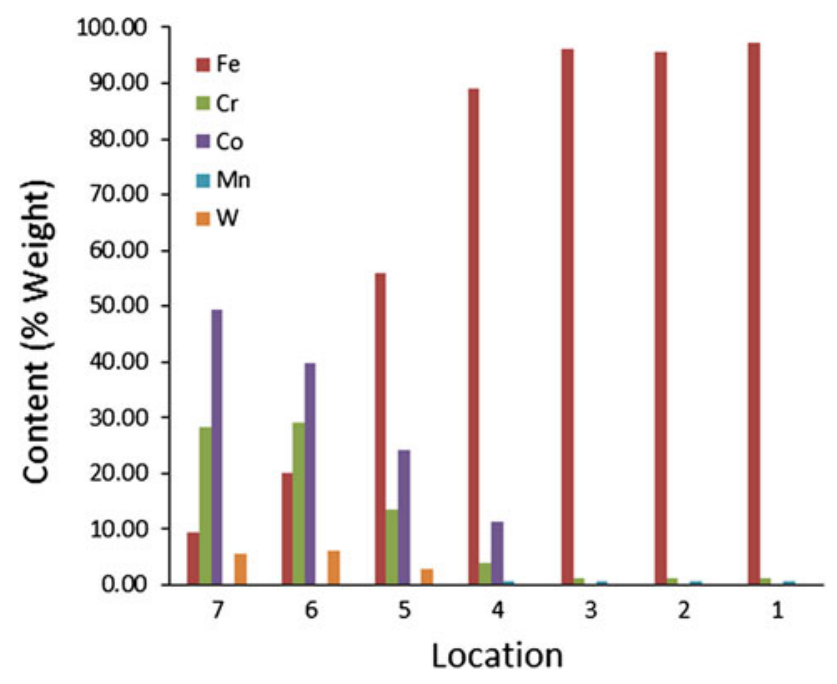

Fig. 5 Indentation at 16 different locations $(4 \times 4$ array $)$ inside $30 \times 30 \mu \mathrm{m}^{2}$ area. Distance of each location was $7 \mu \mathrm{m}$ in $x$ and $y$ direction

$\frac{1}{E_{\mathrm{eff}}}=\frac{1-v^{2}}{E}+\frac{1-v_{\mathrm{i}}^{2}}{E_{\mathrm{i}}}$,

where $E$ and $v$ are the elastic modulus and Poisson's ratio for the specimen, and $E_{\mathrm{i}}$ and $v_{\mathrm{i}}$ are the elastic modulus and Poisson's ratio of the indenter, respectively. For diamond, the value of $E_{\mathrm{i}}=1,141 \mathrm{GPa}$ and that of $v_{\mathrm{i}}=0.07$ [18].

\section{Hardness and Elastic Modulus Measurement}

Hardness and elastic modulus measurements using a Hysitron TI 700 Ubi Nanomechanical test instrument were performed in two stages. The first stage was the load verification stage, where series of indentations were performed on as-received AISI 4130 steel that has been polished using OPS suspension and etched, by multiple loads ranging from 2 to $8 \mathrm{mN}$ with $1 \mathrm{mN}$ interval on ferrite and pearlite phases. For each loading, a cycle of holding time of $1 \mathrm{~s}$ and unloading to $45 \%$ of complete unloading curve was carried out before continuously applying sequence of higher load. Both the loading and unloading rates applied were $0.2 \mathrm{mN} / \mathrm{s}$. The purpose of this stage was to find the suitable load that will produce indentation, which is less affected by strengthening mechanism induced in the material when applied load interacts with microstructure [19]. Second stage of measurement consisted of applying a suitable load as obtained from the first stage, on polished laser-clad specimen (using OPS suspension) without etching to maintain low roughness level to obtain reliable indentation. Indentation configuration is shown in Fig. 5. It is evident from several studies [20-22] that high roughness level deviates from the calculated contact depth, which in turn deviates from the calculated hardness and elastic modulus

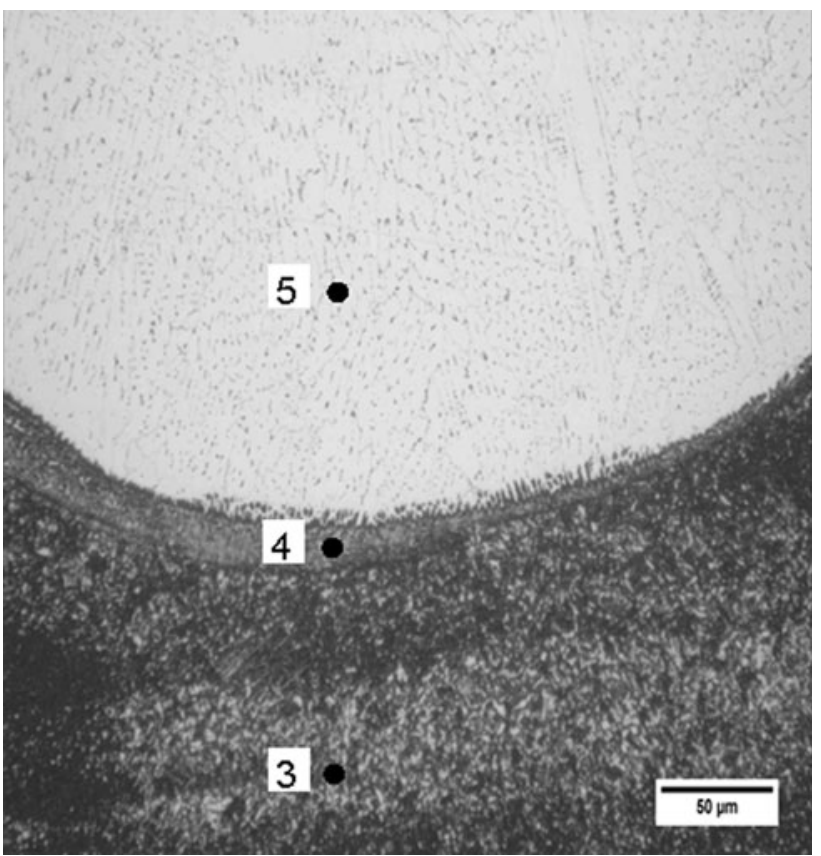

Fig. 6 EDS analysis result based on the measurements at different locations, see Figs. 3 and 4

values. The studies have proven that deviation is more severe when low indentation load is applied. One study [22] suggested that surface asperity less than $30 \mathrm{~nm}$ is adequate to produce reliable hardness and elastic modulus information when using the Oliver-Pharr method. Each indentation was performed using Berkovich-type indenter with tip radius of $50 \mathrm{~nm}$. The Poisson ratio of AISI 4130 steel used in the calculation of elastic modulus was 0.29 [23].

\section{Results and Discussion}

\section{Chemical Elements Distribution}

The result of the EDS measurement (Fig. 6) with reference to measurement location refer to Fig. 3, showed that at location 7, which was located further into coating region, $\mathrm{Co}, \mathrm{Cr}$ and $\mathrm{W}$ were the dominant elements that constituted Stellite 6 coating. A mixture of $\mathrm{Fe}, \mathrm{Cr}$, and Co presents at location 4 and 5 at a coating region close to interface (Fig. 4), where Fe element presents more than $\mathrm{Co}$ and $\mathrm{Cr}$. Further down in substrate region, Fe element dominantly constituted the bulk material of AISI 4130 steel.

\section{Microstructure and Micro Vickers Hardness}

The microstructure of Stellite 6 coating obtained in this experiment was a mixture of dendrites and inter-dendritic structure formed by a eutectic reaction (Fig. 7). Several studies on laser cladding of Stellite 6 show that dendritic 


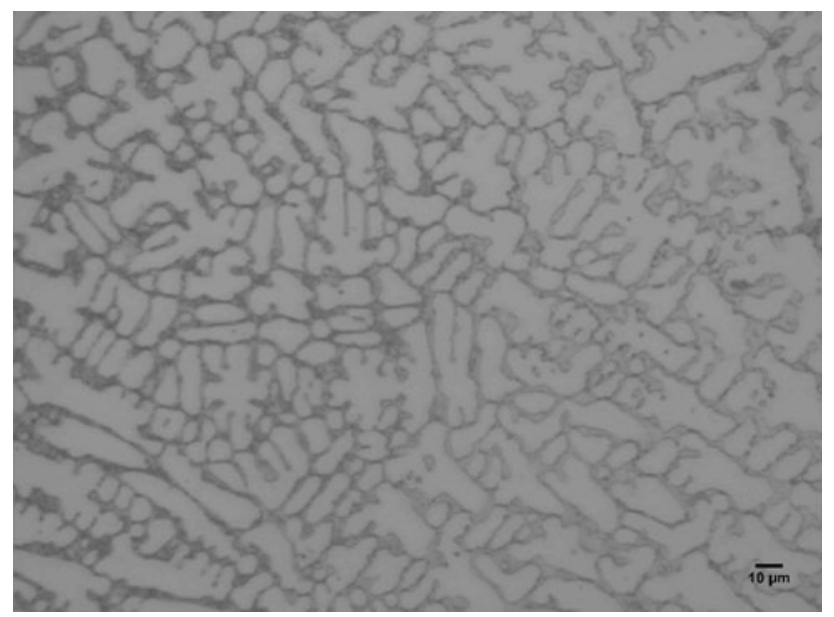

Fig. 7 Microstructures of coating, consists of dendrite structure (bright colour) and inter dendritic structure (dark colour)

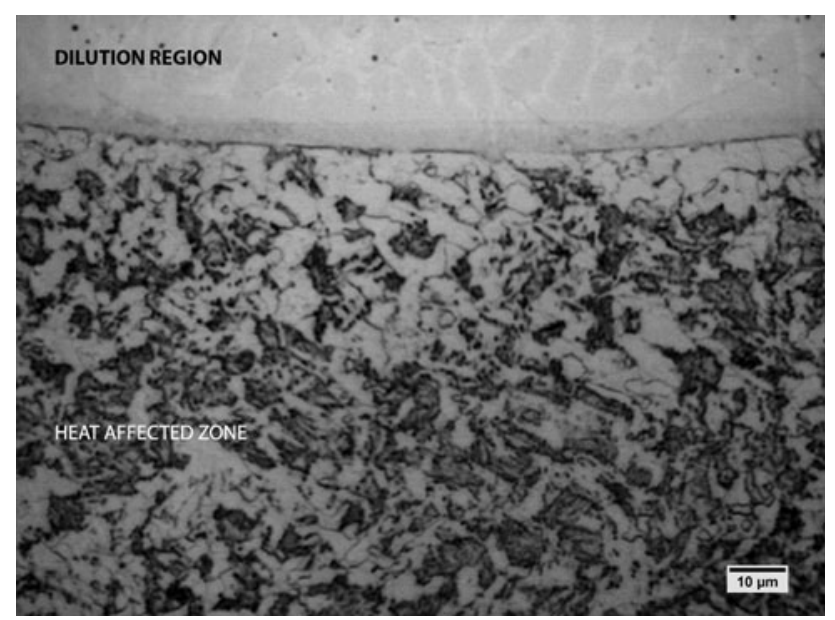

Fig. 8 Microstructures of HAZ, consists of ferrite (white colour), martensite (grey colour) and pearlite (black)

structure is rich with cobalt in the form of $\alpha \mathrm{Co}$, while dark coloured structures are carbides in the form of $\mathrm{M}_{7} \mathrm{C}_{3}[24$, 25], $\mathrm{M}_{23} \mathrm{C}_{6}[6,24]$ and $\mathrm{Co}_{6} \mathrm{~W}_{6} \mathrm{C}[6,24]$, where $\mathrm{M}$ represents $\mathrm{Cr}$, Co and W. Figure 8 shows the microstructures in the HAZ. Phase identification was confirmed by applying hardness test using 5-g load, to phases with the three different colours and comparing the results with the hardness values of ferrite, pearlite and martensite measured in asreceived and quenched round bar AISI 4130 specimens. The hardness of ferrite, pearlite and martensite measured in actual specimen were between 200 and $250 \mathrm{HV}$ for ferrite phase; between 250 and $300 \mathrm{HV}$ for pearlite phase; and between 550 and $600 \mathrm{HV}$ for martensite phase. Based on the hardness test results, the microstructure of HAZ in the vicinity of interface between coating and substrate was identified as ferrite (white colour), martensite (grey colour) and pearlite (black).

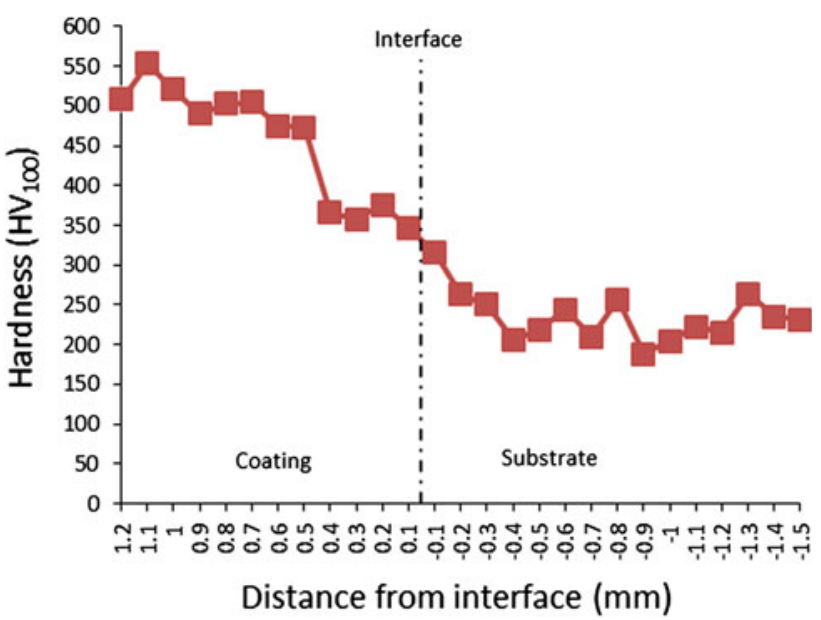

Fig. 9 Hardness profile at the vicinity of the interface of the laserclad specimen

Observation on hardness profile in Fig. 9 shows that hardness level of dilution region (around $350 \mathrm{HV}$ ) is lower than that of the bulk of coating (around $500 \mathrm{HV}$ ). It is evident from Fig. 9, the thickness of dilution region in this experiment is approximately $0.4 \mathrm{~mm}$, indicated by stable hardness level at location up to $0.4 \mathrm{~mm}$ from interface, followed by leap of hardness value starting at distance of $0.5 \mathrm{~mm}$ from the interface. Lower hardness level of the diluted region was because region contains less carbide-forming elements $(\mathrm{Cr}$, $\mathrm{Co}$ and $\mathrm{W}$ ) and more of Fe element compared with bulk of coating above the dilution region. Similar hardness profile was also observed in the substrate region where hardness level increases from 205 to $265 \mathrm{HV}$ as the result of the presence of ferrite and pearlite phase, to around $350 \mathrm{HV}$ as a result of the occurrence of martensite structure together with ferrite and pearlite phases, in the HAZ (Fig. 8).

Nanoindentation

\section{Load Verification Stage}

In the load verification stage, indentations were performed on ferrite and pearlite phases (Fig. 10) by applying multiple loadings on each indentation site. The roughness values (Ra) of the two phases were 6.45 and $16.15 \mathrm{~nm}$ for ferrite and pearlite phases, respectively. From Fig. 11, it was noted that the elastic moduli of the two phase calculated using Eq 6 were changed by increasing the indentation load. For ferrite phase, the effective modulus decreases until load of $5 \mathrm{mN}$ and shows an increase when the load increased towards $8 \mathrm{mN}$. In contrast to ferrite, the effective elastic modulus of pearlite was found to be increasing when the load increased towards $8 \mathrm{mN}$. The changes of effective elastic moduli when load increases are expected to occur due to indentation interaction with grain of the 


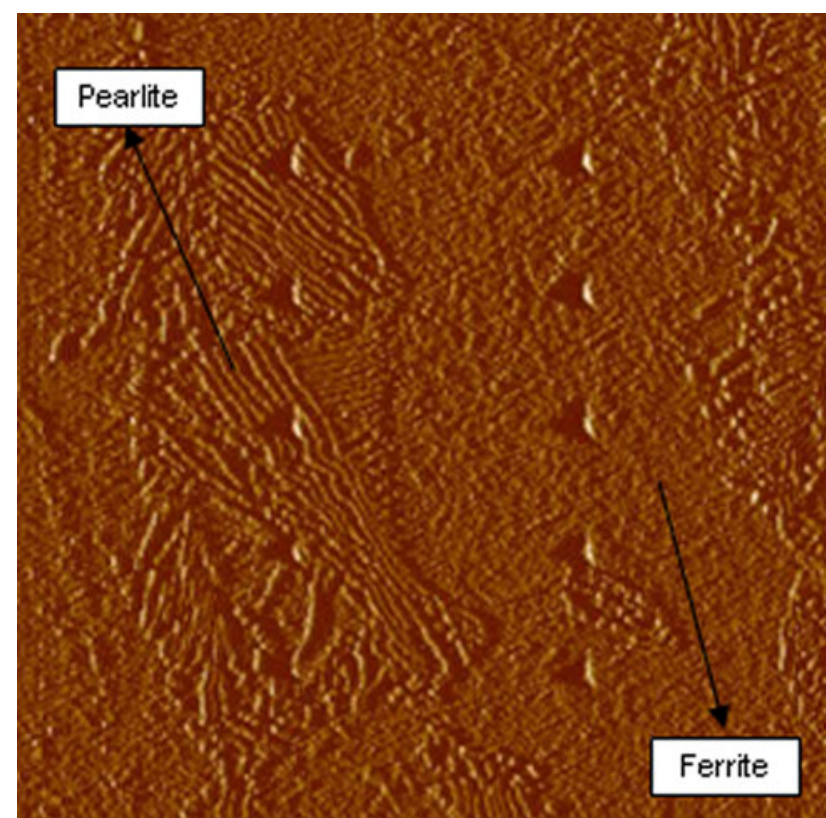

Fig. 10 Indentations on ferrite and pearlite phase in $30 \times 30 \mu \mathrm{m}^{2}$ area

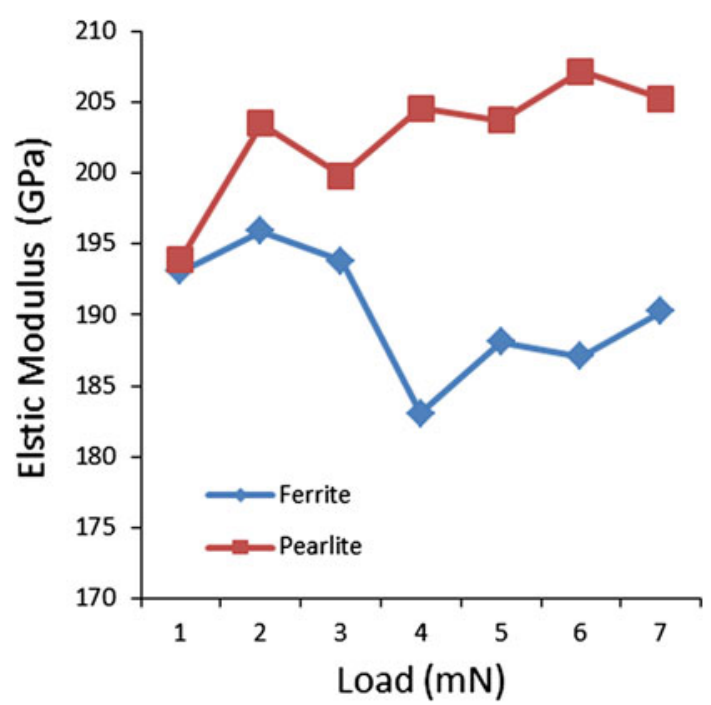

Fig. 11 Average elastic moduli under different loads

material [19]. From experiment [19], it was found that at low load, plastic zone generated by indentation is within the boundary of single grain, producing low hardness level. When applied load increases, the hardness level will be lowered (material become softer) as long as plastic zone is still within the boundary of single crystal. Further increase in applied load generates larger plastic zone that interacts with adjacent grains which resist the generated plastic zone. As a consequence of more resistance from adjacent grains, the hardness level of the material will increase (material becomes harder).

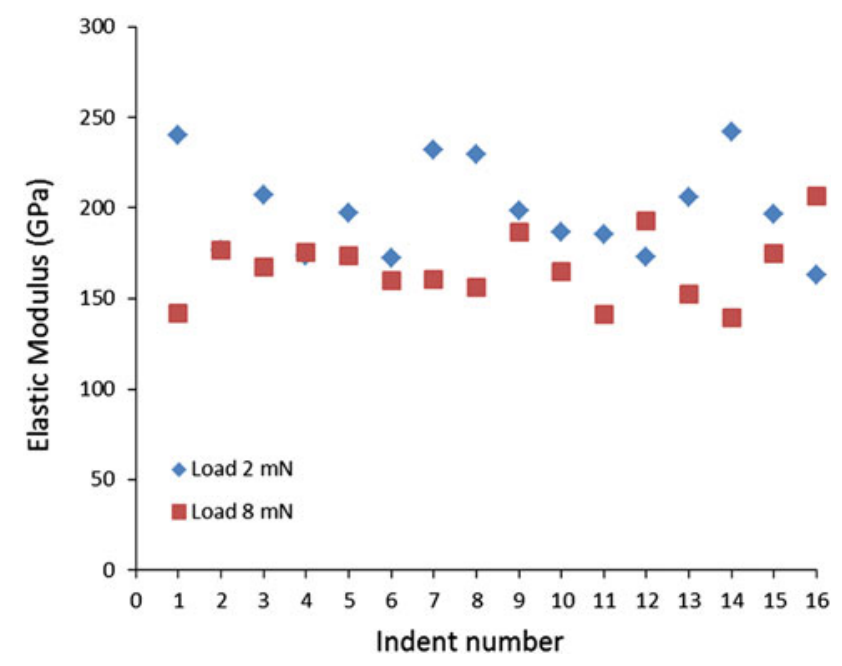

Fig. 12 Elastic modulus of substrate, measured under indentation loads of 2 and $8 \mathrm{mN}$

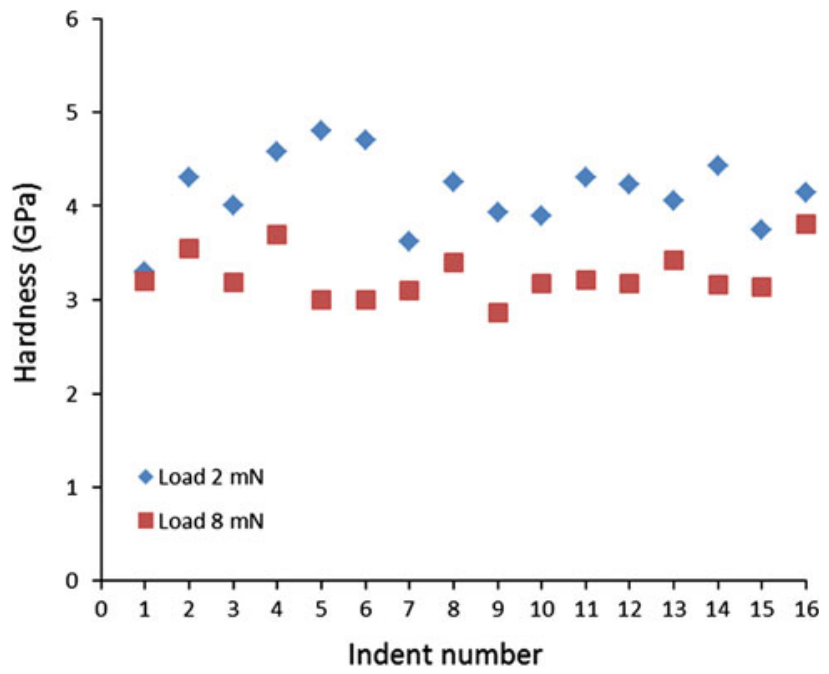

Fig. 13 Hardness of substrate, measured under indentation loads of 2 and $8 \mathrm{mN}$

In order to verify the load that will be applied in measuring elastic modulus of laser-clad specimen, with reference to indentation loading in Fig. 11, a load of $2 \mathrm{mN}$ was applied onto polished and unetched AISI 4130 with surface roughness (Ra) of $7.67 \mathrm{~nm}$. The elastic modulus and hardness values obtained by using these parameters are plotted in Figs. 12 and 13, respectively. The average elastic modulus of AISI 4130 obtained in this experiment was $198.76 \pm 24.96 \mathrm{GPa}$ and in conjunction with hardness information (listed in Table 2), it showed results which are in good agreement with data reported in the literature. The hardness of AISI 4130 steel measured by micro Vickers method (Table 2) can be expressed as $2.26 \pm 0.124 \mathrm{GPa}$ after converting indentation load from kgf to Newton and 
Table 2 Mechanical properties of AISI 4130 steel

\begin{tabular}{llll}
\hline & $\begin{array}{l}\text { Elastic modulus } \\
(\mathrm{GPa})\end{array}$ & Hardness $(\mathrm{HV})$ & $\begin{array}{l}\text { Grain size } \\
(\mu \mathrm{m})\end{array}$ \\
\hline Experiment & $198.76 \pm 24.96^{\mathrm{a}}$ & $225.96 \pm 12.43$ & 15 \\
Ref. [33] & $197^{\mathrm{b}}$ & 245 & 25 \\
\hline
\end{tabular}

${ }^{a}$ Measured by nanoindentation method

${ }^{\mathrm{b}}$ Measured by tensile test method

applying the same micro hardness formula. It was found that this hardness was $54.6 \%$ of average hardness value measured by using nanoindentation method under load of $2 \mathrm{mN}$ (Fig. 13), which is $4.14 \pm 0.385 \mathrm{GPa}$. The mismatch of value in hardness obtained by micro hardness method and nanoindentation method in this experiment and also that reported in other studies on hardness measurement of steel $[19,26]$ was expected to occur due to the difference in the size of indentation of the two methods, which is also known as indentation size effect (ISE). ISE occurs when applying low load and becomes more influencing when the hardness impression is small (indentation depth $<1 \mu \mathrm{m}$ ) [27], where indentation is capable of interacting with single grain of material. However, when load increases, the indentation size and depth also increase until the plastic zone generated by indentation, interacts not only with a single grain but also with the surrounding grains. A previous study on dual-phase steel [19] has shown that when measured using nanoindentation method, martensite structure possesses higher hardness value compared with ferrite; however, when applying higher loads, indentation interacts with both microstructures as a composite (mixture of martensite and ferrite), generating lower hardness level. Another study on stainless steel [26] showed that hardness value measured by micro hardness method was found to be $73 \%$ of the hardness measured by nanoindentation method.

Another issue related to mechanical properties is that yield strength can be estimated from hardness data obtained from nanoindentation using empirical relationship of $H=3 \sigma$ [28].

By implementing this relationship, the average yield strengths observed were 1.38 and $1.08 \mathrm{GPa}$ under indentation loads of 2 and $8 \mathrm{mN}$, respectively. These values are much higher than standard yield strengths of AISI 4130 which are in the range of 355-690 MPa [29]. One of the reasons affecting the high hardness value, which leads to higher yield strength, was that the sharp geometry of Berkovich-type indenter allows some degree of elastic recovery to occur in the specimen during unloading stage [30]; therefore, the boundaries of elastic and plastic deformations cannot be defined clearly.

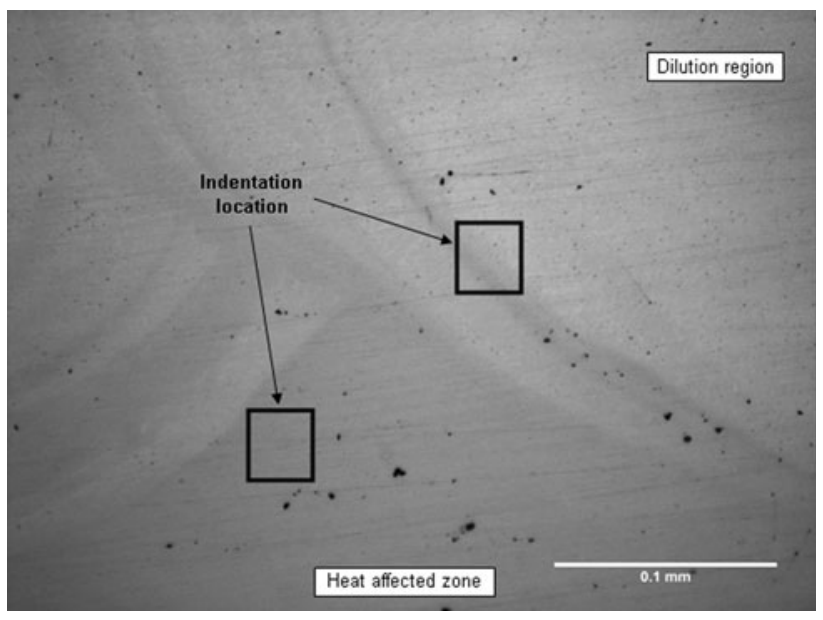

Fig. 14 Indentation locations at the vicinity of dilution region and HAZ

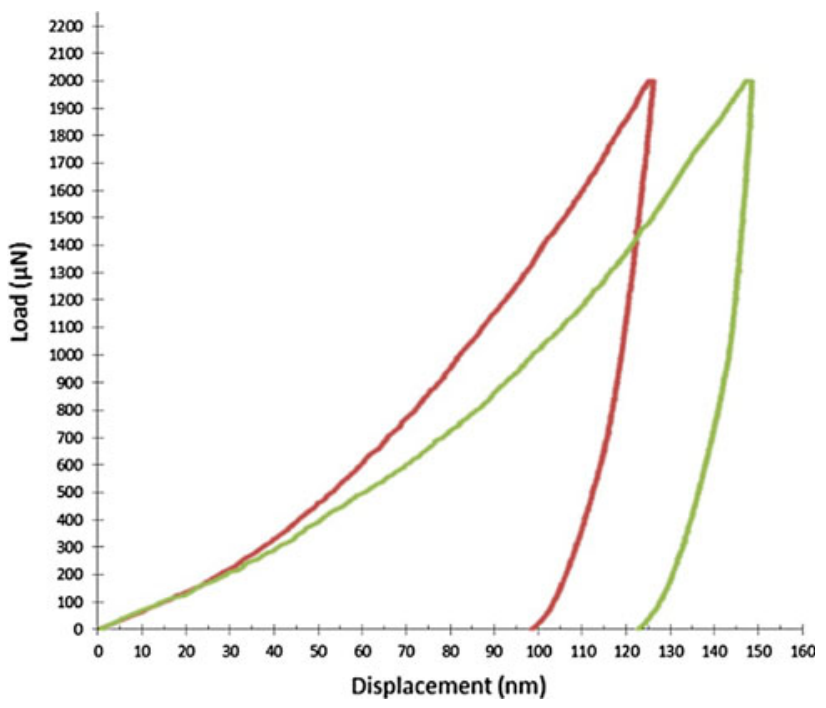

Fig. 15 Typical nanoindentation force-displacement curves of HAZ and dilution region, under indentation load of $2 \mathrm{mN}$

\section{Dilution and HAZ}

Indentations on laser-clad specimens were performed at the dilution region and HAZ (Fig. 14), while the typical loaddisplacement curves of nanoindentations of the two regions are shown in Fig. 15. Based on microstructural observation (Fig. 14), dilution region is located at lower part of coating area, above the coating-substrate interface, while HAZ is in an adjacent zone to dilution region that is located at upper part of substrate below the coating-substrate interface. Dilution region basically is the area where mixing of melted substrate and coating material occurs (Fig. 2), due to heat from laser beam, and the degree of mixing can be identified through EDS analysis. In this experiment, dilution region was dominated by the presence of $\mathrm{Fe}$ element 


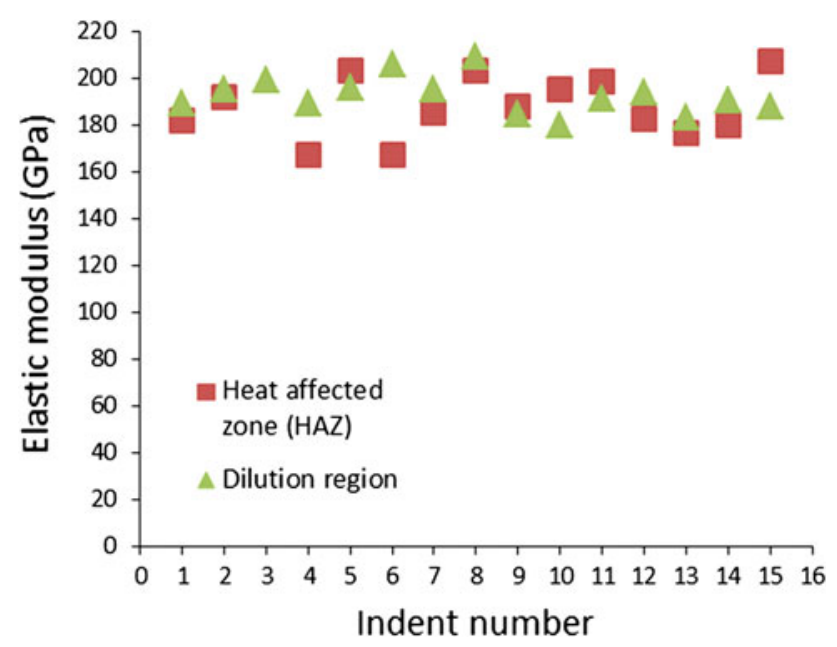

Fig. 16 Measured elastic moduli of the dilution region and the HAZ

Table 3 Elastic modulus of Stellite 6

\begin{tabular}{ll}
\hline & Elastic modulus $(\mathrm{GPa})$ \\
\hline Experiment & $192.62 \pm 7.67^{\mathrm{a}}$ \\
Ref. [34] & $213.7^{\mathrm{b}}$ \\
Ref. [24] & $286 \pm 14^{\mathrm{c}}$ \\
\hline
\end{tabular}

${ }^{a}$ Measurement location at dilution region

b Measurement location information was not clearly indicated, preheat treatment applied

${ }^{c}$ Measurement location at $\gamma$-Co phase (dendrite), no heat treatment applied

(Fig. 6) that implies that the properties of dilution region will be similar to or slightly different from the properties of substrate. It is evident from Fig. 16, dilution region follows this trend, where elastic modulus of dilution region is slightly higher compared to elastic property of the HAZ that lies in substrate area (AISI 4130). The average elastic moduli of the dilution region and the HAZ in this experiment are $192.62 \pm 7.67$ and $189.94 \pm 14.75 \mathrm{GPa}$, respectively. In addition, the implication of mixing effect in the dilution region is evident when comparing the elastic modulus of dilution region with elastic modulus of Stellite 6 coating deposited by thermo mechanical process. It is noted that the elastic modulus of the dilution region is lower compared to the elastic modulus of coating reported in the literature (Table 3).

As regards HAZ, lower elastic modulus (189.94 \pm 14.75 GPa) was found compared with the as-received AISI 4130 steel $(198.76 \pm 24.96)$ due to the presence of martensite structure (Fig. 8), starting at the depth of $10 \mu \mathrm{m}$ from the interface towards HAZ. A previous study [31] showed that martensite structure possesses lower elastic modulus compared with ferrite and pearlite structures because of more distortion occurring in the martensite crystal lattice. Therefore, the elastic modulus of the HAZ is lowered by the addition of martensite structure to ferrite and pearlite structure in the HAZ (Fig. 8).

\section{Conclusion}

An instrumented nanoindentation method using a Berkovich-type indenter was applied to probe elastic and plastic property of the dilution region and the HAZ generated after laser cladding of Stellite 6 powder coating on AISI 4130 steel. The average elastic modulus of the substrate measured under condition of surface roughness of $7.67 \mathrm{~nm}$ and load of $2 \mathrm{mN}$, was found to be $198.76 \pm 24.96 \mathrm{GPa}$ which is in good agreement with the standard elastic modulus of AISI 4130, reported in literature. This also confirms the adequacy of using a Berkovich-type indenter in measuring elastic property, however this type of indenter was found inadequate to probe plastic property of laser-clad structure in this study. The dilution region showed elastic modulus of $192.62 \pm 7.67$, relatively similar to the elastic modulus of the HAZ which was $189.94 \pm 14.75$. Due to the presence of more Fe element in the dilution region, behaves as the substrate which is iron based alloy instead of as coating which is Co based alloy. The elastic modulus of the HAZ was found to be lower compared to that of the substrate which is AISI 4130. The presence of martensite structure in addition to ferrite and pearlite structures lowers the elastic modulus of the HAZ.

\section{References}

1. S. Sun, Y. Durandet, M. Brandt, Parametric investigation of pulsed Nd: YAG laser cladding of stellite 6 on stainless steel. Surf. Coat. Technol. 194, 225-231 (2005)

2. J.L. De Mol Van Otterloo, J.T.M. De Hosson, Microstructural features and mechanical properties of a cobalt-based laser coating. Acta Mater. 45, 1225-1236 (1997)

3. S. Atamert, H. Bhadeshia, Comparison of the microstructures and abrasive wear properties of stellite hardfacing alloys deposited by arc welding and laser cladding. Metall. Mater. Trans. A 20, 1037-1054 (1989)

4. H. So, C.T. Chen, Y.A. Chen, Wear behaviours of laser-clad stellite alloy 6. Wear 192, 78-84 (1996)

5. C.-K. Sha, H.-L. Tsai, Hardfacing characteristics of S42000 stainless steel powder with added silicon nitride using a $\mathrm{CO}_{2}$ laser. Mater. Charact. 52, 341-348 (2004)

6. G. Xu, M. Kutsuna, Z. Liu, K. Yamada, Comparison between diode laser and TIG cladding of Co-based alloys on the SUS403 stainless steel. Surf. Coat. Technol. 201, 1138-1144 (2006)

7. Y.P. Kathuria, Some aspects of laser surface cladding in the turbine industry. Surf. Coat. Technol. 132, 262-269 (2000)

8. L. Shepeleva, B. Medres, W.D. Kaplan, M. Bamberger, A. Weisheit, Laser cladding of turbine blades. Surf. Coat. Technol. 125, 45-48 (2000)

9. R. Pippan, K. Flechsig, F.O. Riemelmoser, Fatigue crack propagation behavior in the vicinity of an interface between materials 
with different yield stresses. Mater. Sci. Eng. A 283, 225-233 (2000)

10. Y. Sugimura, P.G. Lim, C.F. Shih, S. Suresh, Fracture normal to a bimaterial interface: effects of plasticity on crack-tip shielding and amplification. Acta Metall. Mater. 43, 1157-1169 (1995)

11. A.H. Wang, C.S. Xie, J.H. Nie, Bond strength of a laser-clad iron-base alloy coating on $\mathrm{Al}-\mathrm{Si}$ alloy substrate and its fracture behavior. Mater. Charact. 47, 1-7 (2001)

12. Z. Mei, W.Y. Wang, A.H. Wang, Transmission electron microscopy characterization of laser-clad iron-based alloy on AlSi alloy. Mater. Charact. 56, 185-191 (2006)

13. G.M. Pharr, Measurement of mechanical properties by ultra-low load indentation. Mater. Sci. Eng. A 253, 151-159 (1998)

14. Z. Wang, J. Xu, G. Bao, J. Zhang, X. Fang, T. Liu, Fabrication of high-power diesel engine crankshafts by electro-slag casting process. J. Mater. Process. Technol. 182, 588-592 (2007)

15. Z. Yu, X. Xu, Failure analysis of a diesel engine crankshaft. Eng. Fail. Anal. 12, 487-495 (2005)

16. X.-B. Liu, M. Pang, J. Guo, G. Yu, Transmission electron microscopy characterization of laser welding cast Ni-based superalloy K418 turbo disk and alloy steel 42CrMo shaft. J. Alloy. Compd. 461, 648-653 (2008)

17. M.P. Nascimento, R.C. Souza, W.L. Pigatin, H.J.C. Voorwald, Effects of surface treatments on the fatigue strength of AISI 4340 aeronautical steel. Int. J. Fatigue 23, 607-618 (2001)

18. W.C. Oliver, An improved technique for determining hardness and elastic modulus using load and displacement sensing indentation experiments. J. Mater. Res. 7, 1564-1583 (1992)

19. M. Delincé, P.J. Jacques, T. Pardoen, Separation of size-dependent strengthening contributions in fine-grained dual phase steels by nanoindentation. Acta Mater. 54, 3395-3404 (2006)

20. M.S. Bobji, Estimation of hardness by nanoindentation of rough surfaces. J. Mater. Res. 13, 3227-3233 (1998)

21. M. Qasmi, P. Delobelle, Influence of the average roughness Rms on the precision of the Young's modulus and hardness determination using nanoindentation technique with a Berkovich indenter. Surf. Coat. Technol. 201, 1191-1199 (2006)
22. G.B. de Souza, C.E. Foerster, S.L.R. da Silva, C.M. Lepienski, Nanomechanical properties of rough surfaces. Mater. Res. 9, 159-163 (2006)

23. E.F.R.R.T.R. McGrann, B.E. Bodger, W.A. Emery, D.A. Somerville, D.J. Greving, Thermal Spray 1998: Meeting the Challenges of the 21st Century (ASM International, Materials Park, 1998), pp. 557-562

24. U. de Oliveira, V. Ocelík, J.T.M. De Hosson, Residual stress analysis in Co-based laser clad layers by laboratory X-rays and synchrotron diffraction techniques. Surf. Coat. Technol. 201, 533-542 (2006)

25. W.C. Lin, C. Chen, Characteristics of thin surface layers of cobalt-based alloys deposited by laser cladding. Surf. Coat. Technol. 200, 4557-4563 (2006)

26. L. Qian, M. Li, Z. Zhou, H. Yang, X. Shi, Comparison of nanoindentation hardness to microhardness. Surf. Coat. Technol. 195, 264-271 (2005)

27. G.M. Pharr, E.G. Herbert, Y.F. Gao, The indentation size effect: a critical examination of experimental observations and mechanistic interpretations, in Annual Review of Materials Research, ed. by D.R. Clarke, M. Ruhle, F. Zok. Annual Reviews, vol 40 (Palo Alto, 2010), pp. 271-292

28. I.M. Hutchingsa, The contributions of David Tabor to the science of indentation hardness. J. Mater. Res. 24, 581 (2009)

29. G.E. Totten, Steel Heat Treatment: Metallurgy and Technologies, vol. 2 (Taylor \& Francis, Boca Raton, 2007)

30. G.M. Pharr, Understanding nanoindentation unloading curves. J. Mater. Res. 17, 2660-2671 (2002)

31. S.A. Kim, W.L. Johnson, Elastic constants and internal friction of martensitic steel, ferritic-pearlitic steel, and $\alpha$-iron. Mater. Sci. Eng. A 452-453, 633-639 (2007)

32. Z. Fang, Wear Resistance of Powder Metallurgy Alloys (ASM International, Materials Park, 1998)

33. H. Bultel, J.-B. Vogt, Influence of heat treatment on fatigue behaviour of 4130 AISI steel. Proc. Eng. 2, 917-924 (2010)

34. B.V. Cockeram, Fracture toughness testing and toughening mechanisms of some commercial cobalt-free hardfacing alloys. Surf. Coat. Technol. 108-109, 377-384 (1998) 